\section{Iraq's unseen burden of wounded civilians}

The burden of war-related mental disorders is well documented among US veterans (Nature 477, 390-393; 2011), but not among civilians in Iraq. This oversight must be rectified so that adequate medical support can be provided to the Iraqi people.

US combat troops will soon depart Iraq, leaving Iraqis to cope with the consequences of the 2003 invasion. Although the number of violent deaths is falling, civilians have been killed almost every day this year, most of them in coordinated bomb attacks. Roadside blasts cause long-term disabilities and societal effects among injured civilians. However, these have been largely neglected by the media and no systematic surveillance has been undertaken.

Despite Iraq's damaged healthcare system, primary repairs of many injuries are being carried out with acceptable results. But some patients require advanced procedures that are not available in the country. For international aid organizations that are unable to work safely inside Iraq, one operational model is to treat patients outside the country.

Médecins Sans Frontières (MSF; also known as Doctors Without Borders) started a surgical programme in Amman, Jordan, in 2006 to provide functional reconstructive surgery and psychosocial support for Iraqi civilians. Although MSF has managed progressively to increase the capacity of its programme, it can still accommodate only a small fraction of the Iraqi civilians in desperate need of advanced surgical care.

Development of standardized data-collection tools would greatly improve future monitoring of mental health and of explosion injuries. Culturally adequate interventions and tailored support networks are needed to alleviate the longterm physical and psychological repercussions of exposure to war-related trauma. Above all, efforts must concentrate on improving security for civilians. Gilles Guerrier, Emmanuel Baron Epicentre, Paris, France. guerriergilles@gmail.com Rasheed Fakri Médecins Sans Frontières, Amman, Jordan. Isabelle Mouniaman Médecins Sans Frontières, Paris, France.

\section{Brazil's forest code puts wetlands at risk}

Brazil's revisions to its Forest Code threaten not only the Amazon rainforest but also its wetlands (Nature 476, 259-260; 2011). Many Brazilian flood plains extend into neighbouring countries, so they could also be affected.

Seasonal rainfall causes the levels of most Brazilian rivers to fluctuate. Flood plains reach widths of tens of metres along small streams and tens of kilometres along large rivers, and up to $90 \%$ of these dry up during periods of low rainfall.

These wetlands provide the environment and humans with important services, such as water storage, discharge buffering, water clearing, sediment retention, recharging of the groundwater level, local and regional climate regulation, and maintenance of a large biodiversity. Some provide homes and livelihoods for traditional human populations as they harbour important fish stocks and can also be managed for low-density cattle ranching and timber production.

Neither the old nor the new version of the Forest Code specifically mentions wetlands. The old code protects forests along streams and rivers, according to the river's width and maximum water level, thereby integrating and protecting the wetland areas. The new code protects areas only to a poorly defined "regular" water level, opening up opportunities for the destruction of high-lying wetland areas. This will damage the integrity of the remaining low-lying areas, along with most of their benefits for humans and the environment.

The Intergovernmental Panel on Climate Change predicts that large parts of Brazil will experience heavier rainy seasons and more severe dry periods interspersed with heavy rainfall. Buffering by intact wetlands will be increasingly important as water availability and distribution become the limiting factors for agricultural development and the well-being of rural and urban populations. Paulo Teixeira de Sousa Jr National Institute for Science and Technology in Wetlands (INAU), Cuiabá, Mato Grosso, Brazil. pauloteixeiradesousa@gmail.com Maria Teresa Fernandez Piedade National Institute of Amazonian Research (INPA), Manaus, Amazonas, Brazil. Ennio Candotti Museum of Amazônia, Manaus, Amazonas, Brazil.

\section{Small colleges aided by research networks}

As faculty members of primarily undergraduate institutions (PUIs), we have successfully developed research programmes with our students despite funding and collaborator limitations (Nature 477, 239-241; 2011). Long-term research at PUIs is challenging, but feasible.

To improve our research productivity, we have set up collaborative research networks with other PUIs. Through our Ecological Research as Education Network (EREN, comprising 72 PUIs), we are helping each other to develop grant proposals, research protocols, data sets and manuscripts, and are teaching students through multi-institutional, collaborative research (D. R. Bowne et al. BioScience 61, 386-392; 2011).

Internal research funding, including start-up packages, varies widely among institutions.
In a survey of 50 ecology faculty members from PUIs at the Ecological Society of America's 2011 annual meeting, $30 \%$ of respondents reported no internal support for research equipment and supplies, and $51 \%$ said there was none for student-researcher stipends. Inter-institutional networks enable faculty members to share research resources at minimal cost.

PUI faculty members are creative in seeking research funding. For example, the same survey revealed that 94 funding sources had been successfully accessed, including US government agencies.

PUI faculty members often collect long-term data during undergraduate courses and in independent research, although better coordination is needed to enhance the scientific and educational impact of this work. Members of EREN have shared research protocols with many institutions to answer continental-scale questions. Erin S. Lindquist Meredith College, Raleigh, North Carolina, USA.erinlind@meredith.edu Laurel J. Anderson Ohio Wesleyan University, Delaware, Ohio, USA.

Jeffrey A. Simmons Mount St. Mary's University, Emmitsburg, Maryland, USA.

\section{Aboriginal people agreed to DNA study}

As research manager of the Goldfields Land and Sea Council (GLSC), I was involved in your discussion of Aboriginal genome research (Nature 477, 522-523; 2011) and would like to make it clear that the decision to allow analysis of the 90 -year-old hair sample was made by the duly mandated people. The decision took proper account of ethical research practices and of the rights of Aboriginal people to safeguard their cultural heritage.

The GLSC is the representative body for the Aboriginal people 